\title{
Effects of Nanoimprinted Structures on the Performance of Organic Solar Cells
}

\author{
Hardeep Singh Gill,, ${ }^{1,2}$ Lian Li, ${ }^{1,2,3}$ Haizhou Ren, ${ }^{1}$ Ravi Mosurkal $(\mathbb{D})^{3}$ and Jayant Kumar ${ }^{10}{ }^{1,2}$ \\ ${ }^{1}$ Department of Physics, University of Massachusetts Lowell, Lowell, MA 01854, USA \\ ${ }^{2}$ Center for Advanced Materials, University of Massachusetts Lowell, Lowell, MA 01854, USA \\ ${ }^{3}$ US Army Natick Soldier Research, Development and Engineering Center, Natick, MA 01760, USA
}

Correspondence should be addressed to Jayant Kumar; jayant_kumar@uml.edu

Received 9 August 2017; Revised 23 January 2018; Accepted 26 February 2018; Published 11 April 2018

Academic Editor: Chih-Liang Wang

Copyright (C) 2018 Hardeep Singh Gill et al. This is an open access article distributed under the Creative Commons Attribution License, which permits unrestricted use, distribution, and reproduction in any medium, provided the original work is properly cited.

\begin{abstract}
The effect of nanoimprinted structures on the performance of organic bulk heterojunction solar cells was investigated. The nanostructures were formed over the active layer employing the soft lithographic technique. The measured incident photon-tocurrent efficiency revealed that the nanostructured morphology over the active layer can efficiently enhance both light harvesting and charge carrier collection due to improvement of the absorption of incident light and the buried nanostructured cathode, respectively. The devices prepared with the imprinted nanostructures exhibited significantly higher power conversion efficiencies as compared to those of the control cells.
\end{abstract}

Recent advances in material synthesis and device fabrication for the solution processed organic solar cells (OSCs) have led to power conversion efficiencies (PCEs) exceeding $11 \%$ using hole transporting conjugated polymers and electron transporting organic molecules [1-8]. Bulk heterojunctions are formed in the active layers of the OSCs. Even though the device performance of the OSCs has been improved significantly [3-6], their PCEs are still lower than those of their inorganic counterparts, which remain a hindrance towards their commercialization. One of the factors that limit the performance of the OSCs is the relatively lower charge carrier mobility of the organic materials, which results in trapping of the photogenerated charge carriers from the junction to the electrodes $[9,10]$. Hence, the active layer cannot be thick [11-14], and thicker films cannot help to increase the photocurrent and improve the cell performance despite enhanced absorption of light. The active layer thickness constraint imposed on the bulk heterojunction solar cells therefore makes it imperative to develop innovative ways to enhance absorption in the solar spectral range without increasing the film thickness. This dilemma could be resolved by light trapping schemes in the active layer. OSCs fabricated with light trapping nanostructures and thin active layer can achieve absorption equivalent to that of thicker layer, while retaining good charge transport and collection properties.

A few light trapping management techniques have been investigated for enhancing photon absorption and PCEs in OSCs [15-24]. Patterning active layers with gratings or wrinkle-like topography by soft lithography led to light trapping into the active films [17-19]. Other light trapping schemes based on the patterned electrodes were also reported using buried nanoelectrodes [20], microprism substrates [21], and azopolymer based submicrometer relief substrates [2224]. Although the enhancements in light absorption have been demonstrated in those devices, the practical adoption of these light manipulation methods is hindered due to the difficulty of precisely engineering the multiple periodic nanostructures, the incompatibility with the thin organic films, the limited spectral response, and complicated fabrication procedures over large areas.

Nanoimprinting has recently emerged as a promising candidate for fabricating nanostructures $[25,26]$. It offers high throughput and high precision. Surface relief pattern of a stamp can be readily replicated over the active film by thermal-contact printing. Recently, this imprinting method has been applied to the OSCs to improve the PCEs [27, 28]. 


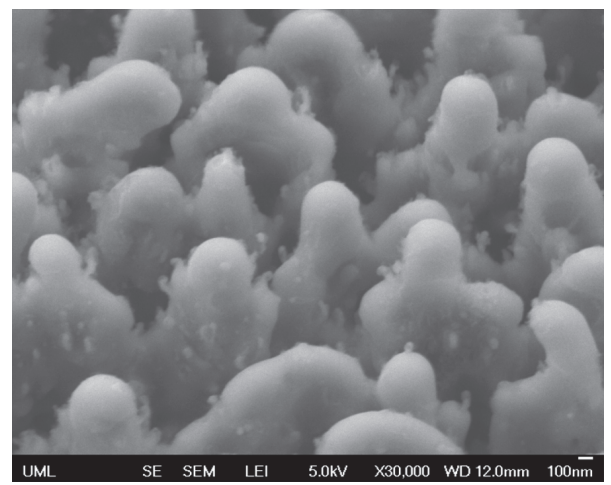

FIGURE 1: SEM image of the silicon nanospikes viewed at a tilted angle of $45^{\circ}$.

More than $11 \%$ enhancements were reported for the nanostructured OSCs as compared to those of the nonstructured ones. Nanospikes created on silicon wafers by near-infrared femtosecond laser pulses have been used for antireflection and light trapping in silicon based photodiodes [28, 29]. In this letter, we report on incorporation of the nanospike structures photofabricated on silicon wafer into the organic photovoltaic cells by nanoimprint technique. The OSCs with the nanostructures exhibited significantly improved photocurrent and PCSs due to enhanced light harvesting and better charge collection.

A femtosecond Ti:sapphire laser (operating at $800 \mathrm{~nm}$ with 100 -femtosecond pulse width and $1 \mathrm{kHz}$ repetition rate) was used to produce the silicon nanospike structures. Silicon wafer was first cleaned with acetone and then rinsed in methanol. The cleaned silicon wafer was immersed in methanol in a Petri dish. The Petri dish was then positioned on a computer controlled $X-Y$ stage. The frequency-doubled laser pulses from a beta barium borate crystal at $400 \mathrm{~nm}$ were normally incident on the surface of the silicon wafer after passing through a lens. The nanospike structure over an area of $1 \mathrm{~cm}^{2}$ was fabricated. The nanostructures were treated with $10 \%$ hydrofluoric acid to remove the very thin oxidized silicon layer and to smooth the nanospikes. Figure 1 shows the SEM image of typical silicon nanospikes viewed at a tilted angle of $45^{\circ}$. The nanospikes are typically a few hundred nanometers in height and several hundred nanometers in width. Because the dimensions of nanospikes are in the visible spectral range, the fabricated silicon nanospikes are able to trap most of the incident light and appear black.

Thermal-contact printing method was utilized to transfer the nanostructures over the active thin films. Indium doped tin oxide (ITO) coated glasses $(10 \Omega / \square)$ were cleaned with detergent and were then sonicated in water, acetone, and isopropanol. All the chemicals used in this study were acquired from Sigma Aldrich and were used without further purification. Poly(3,4-ethylenedioxythiophene):polystyrene sulfonate (PEDOT:PSS) from aqueous solution was first spin-coated on the cleaned ITO substrate at $1200 \mathrm{rpm}$ for 10 seconds and at $3000 \mathrm{rpm}$ for 60 seconds. The PEDOT:PSS coated substrates were then baked at $130^{\circ} \mathrm{C}$ for $15 \mathrm{~min}$ in a vacuum oven. The PEDOT:PSS film was about $40 \mathrm{~nm}$ thick.
Solutions of poly 3-hexyl thiophene (P3HT) : phenyl-C61butyric acid methyl ester (PCBM) (30 mg/mL: $24 \mathrm{mg} / \mathrm{mL}$ ) and P3HT: indene-C60 bis-adduct (ICBA) $(30 \mathrm{mg} / \mathrm{mL}$ : $24 \mathrm{mg} / \mathrm{mL}$ ) were prepared by codissolving the corresponding materials in 1,2-dichlorobenzene, respectively. After filtering the solutions through $0.2 \mu \mathrm{m}$ pore size membrane filters, P3HT:PCBM and P3HT:ICBA thin films were prepared by spin-coating at $800 \mathrm{rpm}$ for 180 seconds on top of the PEDOT:PSS layers, respectively. The resulting blend films were about $260 \mathrm{~nm}$ thick. It is known that P3HT absorbs broadly in visible region from $400 \mathrm{~nm}$ to $650 \mathrm{~nm}$, with a peak around $550 \mathrm{~nm}$. After spin-coating, the nanostructured silicon stamp was brought into conformal contact with the thin active film and annealed at $130^{\circ} \mathrm{C}$ for $30 \mathrm{~min}$ under a pressure around $5 \mathrm{kPa}$. After removal of the silicon stamp, the replica patterns were attained. Aluminum electrodes were deposited on the nanostructured active layers by thermal evaporation. The thickness of aluminum layer was about $100 \mathrm{~nm}$. For comparison, control devices without the nanospike structures were also fabricated.

Scanning electron microscopy (SEM) and atomic force microscopy (AFM) were used to study the nanoimprinted structures on the active layer of P3HT:PCBM. Figures 2(a) and 2(b) show the SEM images of the nanostructured active layer at two different magnifications. These images elucidate that nanostructures from the silicon stamp were transferred to the active layer. Figures 3(a) and 3(b) illustrate the topographic and 3D AFM images of the nanostructured active layers. The imprinted active layers exhibited nanotextured structures similar to those of the stamp of a few hundred nanometers high and several hundred nanometers wide. Similar nanopatterns were obtained on the P3HT:ICBA layer.

Figure 4 depicts the absorption spectra of the control and nanostructured P3HT:PCBM and P3HT:ICBA films. Films with the nanostructures scatter more light in comparison against the control samples without the structures. The incident photon-to-current efficiency (IPCE) measurements on the fabricated solar cells were also performed. Figures 5(a) and 5(b) exhibit the IPCE spectra of the nanostructured P3HT:PCBM and P3HT:ICBA OSCs and their corresponding control devices, respectively. The solar cells with the nanostructures yielded about $30 \%$ improvement in the quantum 


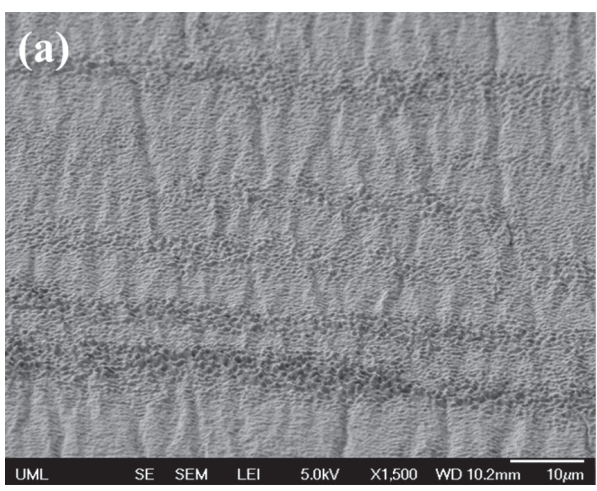

(a)

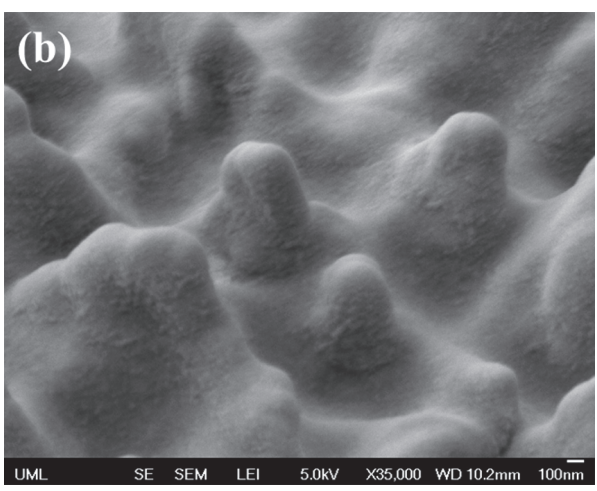

(b)

FIGURE 2: SEM images of the structured active layer of P3HT:PCBM viewed at the tilted angles of $45^{\circ}$ with two different magnifications of (a) $1,500 \mathrm{x}$ and (b) 35,000x.

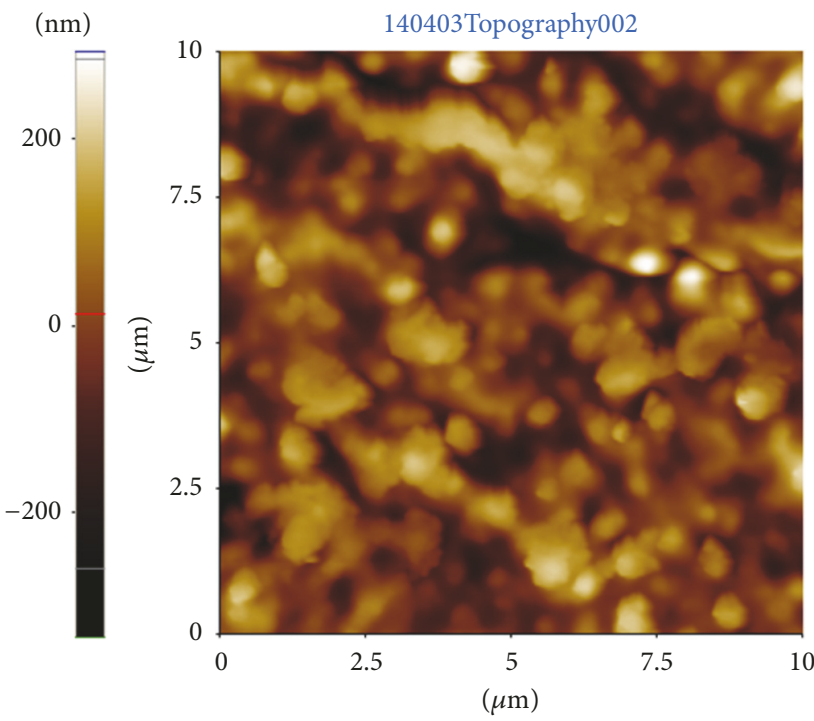

(a)

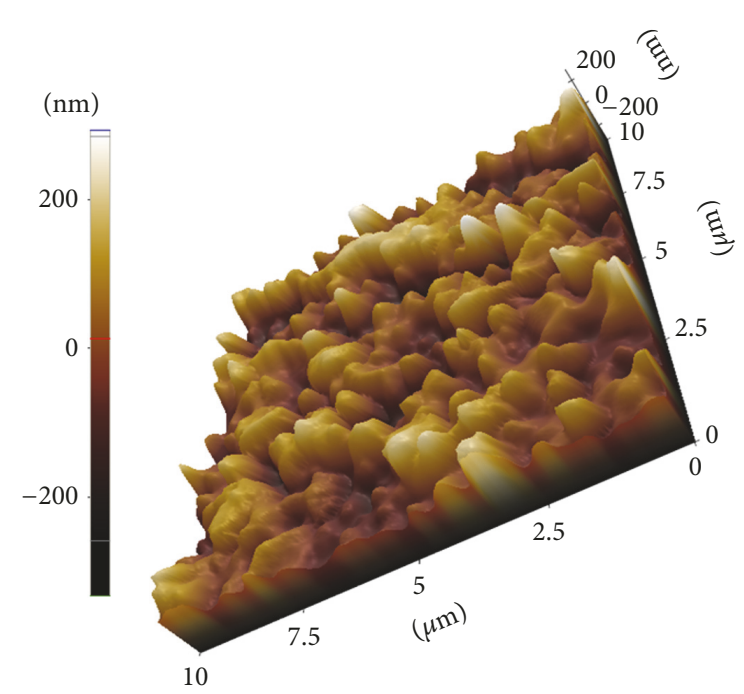

(b)

FIgURE 3: (a) Topographic and (b) 3D AFM images of the nanostructured active layer of P3HT:PCBM.

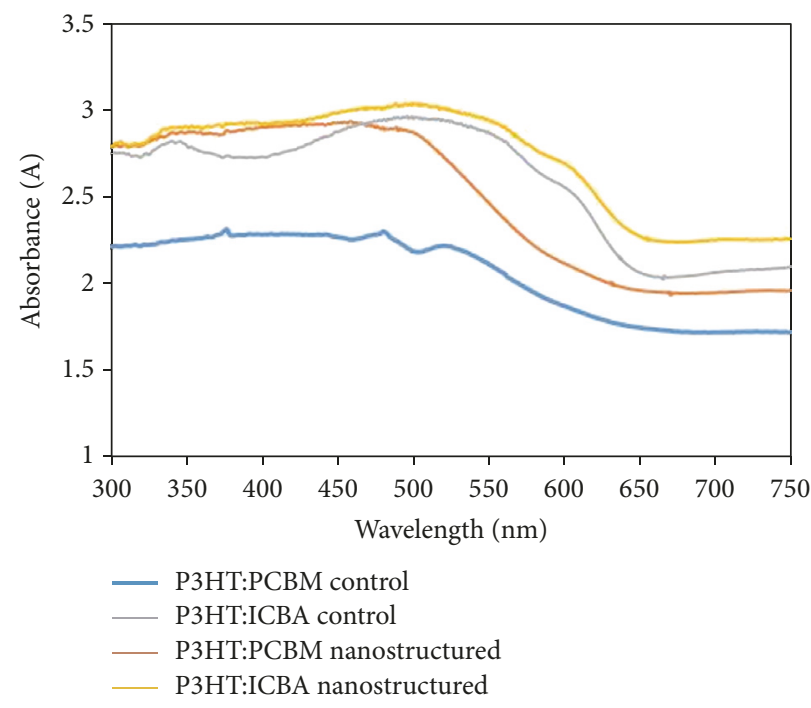

FIGURE 4: Absorption spectra comparison of control and nanostructured films. 


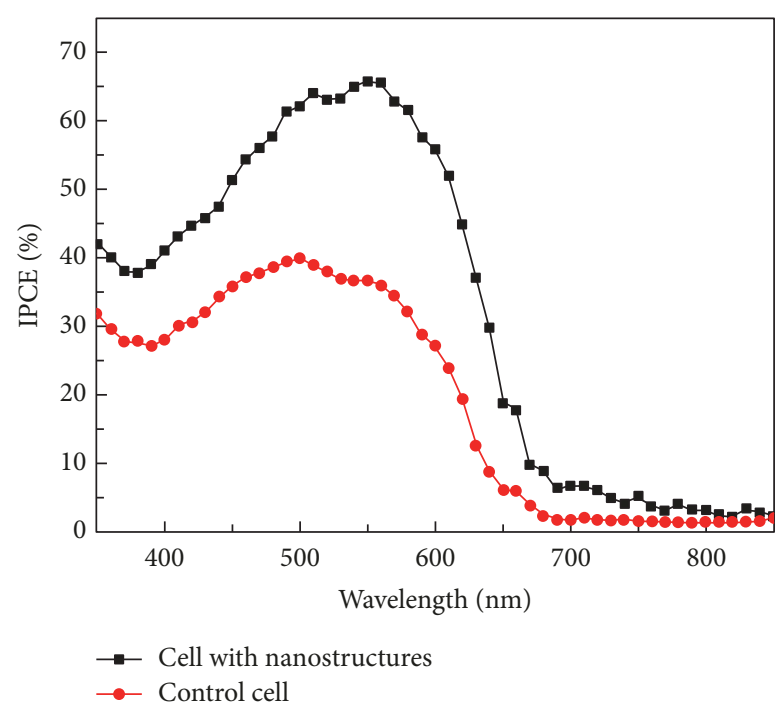

(a)

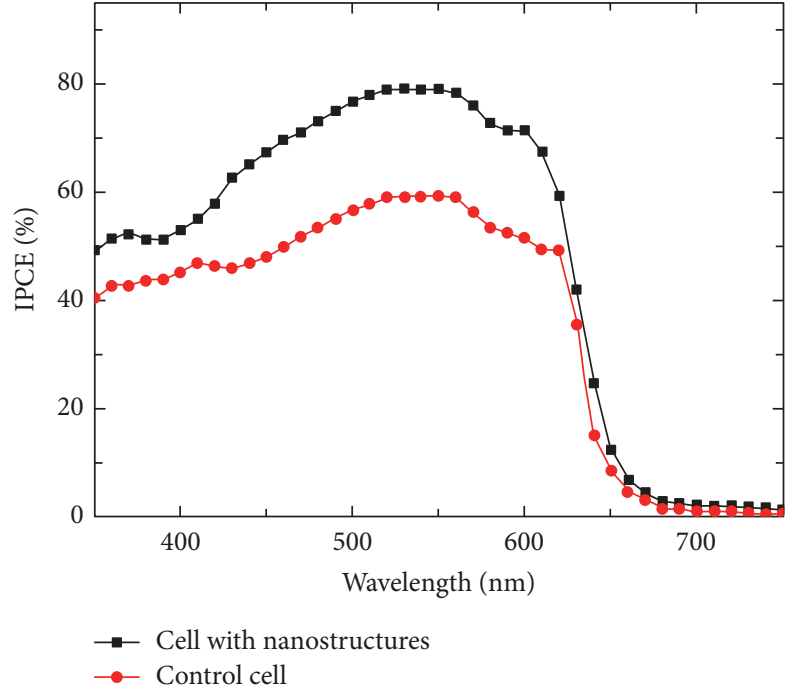

(b)

Figure 5: IPCE spectra of (a) the P3HT:PCBM and (b) the P3HT:ICBA solar cells with and without nanoimprinted structures.

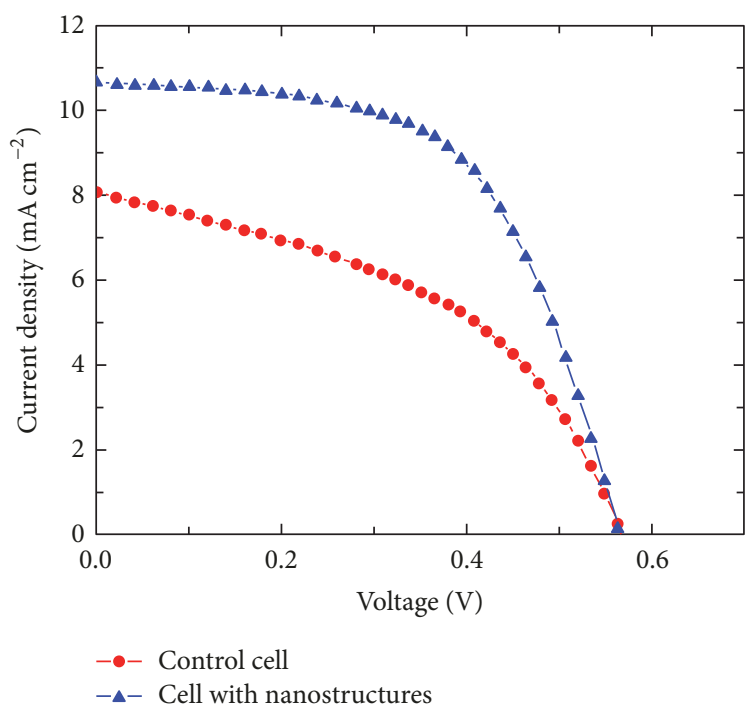

(a)

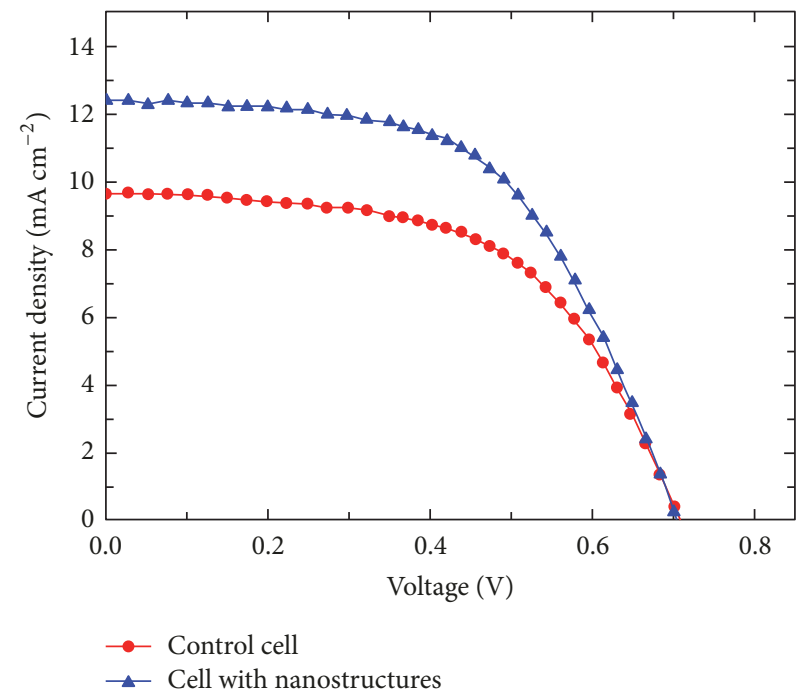

(b)

FIgUre 6: $J-V$ characteristics of (a) the P3HT:PCBM and (b) the P3HT:ICBA solar cells with and without the nanostructures.

efficiency against the control cells without the structures. The increase in the IPCE of the nanostructured solar cells over the wavelength range of $350-700 \mathrm{~nm}$ contributes to the short-circuit current density (Jsc) improvement. This enhancement of the nanotextured OSCs indicated that the nanoimprinted structures can increase optical path length and provide efficient light trapping by multireflection from the textured surface and total internal reflection.

Photovoltaic performance of the solar cells was characterized under 1 sun $\left(100 \mathrm{~mW} / \mathrm{cm}^{2}\right)$ AM $1.5 \mathrm{G}$ solar irradiation. A black shadow mask with an area of $0.08 \mathrm{~cm}^{2}$ was used for the characterization. Figures 6(a) and 6(b) show the $J$ $V$ characteristics of the P3HT:PCBM and P3HT:ICBA solar cells with and without the nanostructures, respectively.
The photovoltaic characteristics of the solar cells are summarized in Table 1. The control cells made of P3HT:PCBM and P3HT:ICBA only yielded PCEs of $1.97 \%$ and $3.87 \%$ with $J \mathrm{sc}$ of $8.10 \mathrm{~mA} \mathrm{~cm}^{-2}$ and $9.70 \mathrm{~mA} \mathrm{~cm}^{-2}$, the open-circuit voltage $(\mathrm{Voc})$ of $0.56 \mathrm{~V}$ and $0.70 \mathrm{~V}$, and the fill-factor $(\mathrm{FF})$ of 0.43 and 0.56, respectively. The nanostructured P3HT:PCBM and P3HT:ICBA solar cells exhibited significantly improved PCEs as compared to those of the control ones. The nanostructured P3HT:PCBM and P3HT:ICBA devices yielded PCEs of $3.50 \%$ and $5.38 \%$, respectively. Significant performance enhancements have been achieved for the nanostructured OSCs as compared to those of the nonpatterned ones. The increases in PCEs are mainly ascribed to the increase in Jsc plus improvement in FF. 
TABLE 1: Performance characteristics of the P3HT:PCBM and P3HT:ICBA solar cells with and without the nanostructures.

\begin{tabular}{lcccc}
\hline Sample & $J_{\mathrm{sc}}\left(\mathrm{mA} / \mathrm{cm}^{2}\right)$ & $V_{\mathrm{oc}}(\mathrm{V})$ & FF $(\%)$ & PCE $(\%)$ \\
\hline & & $P 3 H T: P C B M$ & & \\
Control & $8.10 \pm 0.05$ & $0.56 \pm 0.03$ & $43.30 \pm 0.02$ & $1.97 \pm 0.01$ \\
Nanostructured & $10.70 \pm 0.03$ & $0.56 \pm 0.02$ & $58.40 \pm 0.02$ & $3.50 \pm 0.01$ \\
\hline & & $P 3 H T: I C B A$ & & \\
Control & $9.70 \pm 0.05$ & $0.70 \pm 0.02$ & $56.10 \pm 0.03$ & $3.87 \pm 0.02$ \\
Nanostructured & $12.40 \pm 0.03$ & $0.70 \pm 0.02$ & $61.80 \pm 0.04$ & $5.38 \pm 0.02$ \\
\hline
\end{tabular}

As shown in Figures 2 and 3, the nanoimprinting induces the textured surface over the active layer with dimensions in the visible wavelength region, leading to scattering of incident light within the layer. Hence, the optical path inside the active layer is increased, resulting in higher absorption and higher charge generation. This leads to enhancement of Jsc and PCE. Moreover, the nanoimprinted surface will also make the aluminum electrode to be textured and buried inside the active film. Since FF is limited by the carrier drift length, [28] defined as a product of the carrier mobility, the carrier recombination lifetime, and the electric field, the increase in FF upon nanoimprinting can be attributed to the better charge extraction/collection. The nanotextured electrode provides larger surface area in contact with the active materials and helps shortening the travelling distance of the charge carriers to the corresponding electrodes, hence improving the charge collection and significant improvement of photovoltaic performance.

In summary, the OSCs with the nanospike structures were successfully fabricated using thermal-contact printing technique. Significant enhancement of the photovoltaic performance of the nanoimprinted solar cells was achieved due to effective light trapping and increase in optical path length from the textured active layer and efficient charge carrier collection from the buried nanostructured aluminum electrode. This simple technique can be adapted for roll-toroll manufacturing. This work can provide an effective way to further enhance the OSC performance by optimization of processing protocols of given materials.

\section{Additional Points}

Impact Statement. Significant enhancement of the photovoltaic performance of the nanoimprinted solar cells was achieved due to effective light trapping and increase in optical path length from the textured active layer.

\section{Conflicts of Interest}

The authors declare that they have no conflicts of interest.

\section{Acknowledgments}

This work was supported as part of Polymer-Based Materials for Harvesting Solar Energy, an Energy Frontier Research Center funded by the U.S. Department of Energy, Office of Science, and Basic Energy Sciences under Award no. DESC0001087. This research was also supported in part by an appointment to the Faculty Research Participation Program at the U.S. Army Natick Soldier Research, Development and Engineering Center (NSRDEC) administered by the Oak Ridge Institute for Science and Education through an interagency agreement between the U.S. Department of Energy and NSRDEC. Hardeep Singh Gill will like to thank the Tripathy Summer Graduate Fellowship from the Center for Advanced Materials at the University of Massachusetts Lowell.

\section{References}

[1] C. W. Tang, “Two-layer organic photovoltaic cell," Applied Physics Letters, vol. 48, no. 2, pp. 183-185, 1986.

[2] H.-Y. Chen, J. Hou, S. Zhang et al., "Polymer solar cells with enhanced open-circuit voltage and efficiency," Nature Photonics, vol. 3, no. 11, pp. 649-653, 2009.

[3] Z. He, C. Zhong, X. Huang et al., "Simultaneous enhancement of open-circuit voltage, short-circuit current density, and fill factor in polymer solar cells," Advanced Materials, vol. 23, no. 40, pp. 4636-4643, 2011.

[4] J. Zhao, Y. Li, G. Yang et al., "Efficient organic solar cells processed from hydrocarbon solvents," Nature Energy, vol. 1, no. 2, p. 15027, 2016.

[5] G. Luo, X. Ren, S. Zhang et al., "Recent advances in organic photovoltaics: device structure and optical engineering optimization on the nanoscale," Small, vol. 12, no. 12, pp. 1547-1571, 2016.

[6] Z. Zheng, O. M. Awartani, B. Gautam et al., "Efficient charge transfer and fine-tuned energy level alignment in a THF-processed fullerene-free organic solar cell with $11.3 \%$ efficiency," Advanced Materials, vol. 29, no. 5, Article ID 1604241, 2017.

[7] S. Satapathi, H. S. Gill, L. Li, L. Samuelson, J. Kumar, and R. Mosurkal, "Synthesis of nanoparticles of P3HT and PCBM for optimizing morphology in polymeric solar cells," Applied Surface Science, vol. 323, pp. 13-18, 2014.

[8] H. S. Gill, S. Thota, L. Li, A. Kokil, R. Mosurkal, and J. Kumar, "Performance enhancement of fullerene based solar cells upon NIR laser irradiation," RSC Advances, vol. 5, no. 60, pp. 4852648532, 2015.

[9] A. Kokil, K. Yang, and J. Kumar, "Techniques for characterization of charge carrier mobility in organic semiconductors," Journal of Polymer Science Part B: Polymer Physics, vol. 50, no. 15, pp. 1130-1144, 2012.

[10] F. C. Krebs, "Fabrication and processing of polymer solar cells: a review of printing and coating techniques," Solar Energy Materials \& Solar Cells, vol. 93, no. 4, pp. 394-412, 2009.

[11] S. Basu Mallick, N. P. Sergeant, M. Agrawal, J.-Y. Lee, and P. Peumans, "Coherent light trapping in thin-film photovoltaics," MRS Bulletin, vol. 36, no. 6, pp. 453-460, 2011. 
[12] G. Li, V. Shrotriya, Y. Yao, and Y. Yang, "Investigation of annealing effects and film thickness dependence of polymer solar cells based on poly(3-hexylthiophene)," Journal of Applied Physics, vol. 98, no. 4, Article ID 043704, 2005.

[13] K. M. Coakley and M. D. McGehee, "Conjugated polymer photovoltaic cells," Chemistry of Materials, vol. 16, no. 23, pp. 4533-4542, 2004.

[14] D.-H. Ko, J. R. Tumbleston, A. Gadisa et al., "Light-trapping nano-structures in organic photovoltaic cells," Journal of Materials Chemistry, vol. 21, no. 41, pp. 16293-16303, 2011.

[15] S.-I. Na, S.-S. Kim, S.-S. Kwon et al., "Surface relief gratings on poly(3-hexylthiophene) and fullerene blends for efficient organic solar cells," Applied Physics Letters, vol. 91, no. 17, Article ID 173509, 2007.

[16] J. H. Lee, D. W. Kim, H. Jang et al., "Enhanced solar-cell efficiency in bulk-heterojunction polymer systems obtained by nanoimprinting with commercially available AAO membrane filters," Small, vol. 5, no. 19, pp. 2139-2143, 2009.

[17] C. F. Shih, K. T. Hung, J. W. Wu, C. Y. Hsiao, and W. M. $\mathrm{Li}$, "Efficiency improvement of blended poly(3-hexylthiophene) and 1-(3-methoxycarbonyl)-propyl-1-phenyl- $(6,6)$ C61 solar cells by nanoimprinting," Applied Physics Letters, vol. 94, no. 14, Article ID 143505, 2009.

[18] M. Niggemann, M. Glatthaar, A. Gombert, A. Hinsch, and V. Wittwer, "Diffraction gratings and buried nano-electrodes Architectures for organic solar cells," Thin Solid Films, vol. 451452, pp. 619-623, 2004.

[19] M. Niggemann, M. Glatthaar, P. Lewer, C. Müller, J. Wagner, and A. Gombert, "Functional microprism substrate for organic solar cells," Thin Solid Films, vol. 511-512, pp. 628-633, 2006.

[20] C. Cocoyer, L. Rocha, C. Fiorini-Debuisschert et al., "Implementation of a submicrometer patterning technique in azopolymer films towards optimization of photovoltaic solar cells efficiency," Thin Solid Films, vol. 511-512, pp. 517-522, 2006.

[21] D. H. Wang, D.-G. Choi, K.-J. Lee, S. H. Im, O. O. Park, and J. H. Park, "Unexpected solid-solid intermixing in a bilayer of poly(3-hexylthiophene) and [6,6]-phenyl C61-butyric acidmethyl ester via stamping transfer," Organic Electronics, vol. 11, no. 8, pp. 1376-1380, 2010.

[22] C. Cocoyer, L. Rocha, L. Sicot et al., "Implementation of submicrometric periodic surface structures toward improvement of organic-solar-cell performances," Applied Physics Letters, vol. 88, no. 13, Article ID 133108, 2006.

[23] S.-B. Rim, S. Zhao, S. R. Scully, M. D. McGehee, and P. Peumans, "An effective light trapping configuration for thin-film solar cells," Applied Physics Letters, vol. 91, no. 24, Article ID 243501, 2007.

[24] L. J. Guo, "Nanoimprint lithography: methods and material requirements," Advanced Materials, vol. 19, no. 4, pp. 495-513, 2007.

[25] H. Schift, "Nanoimprint lithography: an old story in modern times? A review," Journal of Vacuum Science \& Technology B, vol. 26, no. 2, pp. 458-480, 2008.

[26] M. Schmidt, P. Lugli, G. Ulisse, C. Ciceroni, and F. Brunetti, "Nanopatterning of P3HT:PCBM for organic solar cell realization," in Proceedings of the 15th IEEE International Conference on Nanotechnology, IEEE-NANO 2015, pp. 1366-1369, Italy, July 2015.

[27] R. A. Myers, R. Farrell, A. M. Karger, J. E. Carey, and E. Mazur, "Enhancing near-infrared avalanche photodiode performance by femtosecond laser microstructuring," Applied Optics, vol. 45, no. 35, pp. 8825-8831, 2006.
[28] J. E. Carey, C. H. Crouch, M. Shen, and E. Mazur, "Visible and near-infrared responsivity of femtosecond-laser microstructured silicon photodiodes," Optics Expresss, vol. 30, no. 14, pp. 1773-1775, 2005.

[29] W. Ma, C. Y. Yang, X. Gong, K. Lee, and A. J. Heeger, “Thermally stable, efficient polymer solar cells with nanoscale control of the interpenetrating network morphology," Advanced Functional Materials, vol. 15, no. 10, pp. 1617-1622, 2005. 


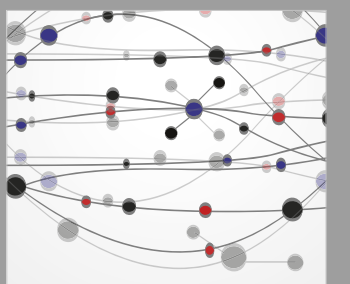

The Scientific World Journal
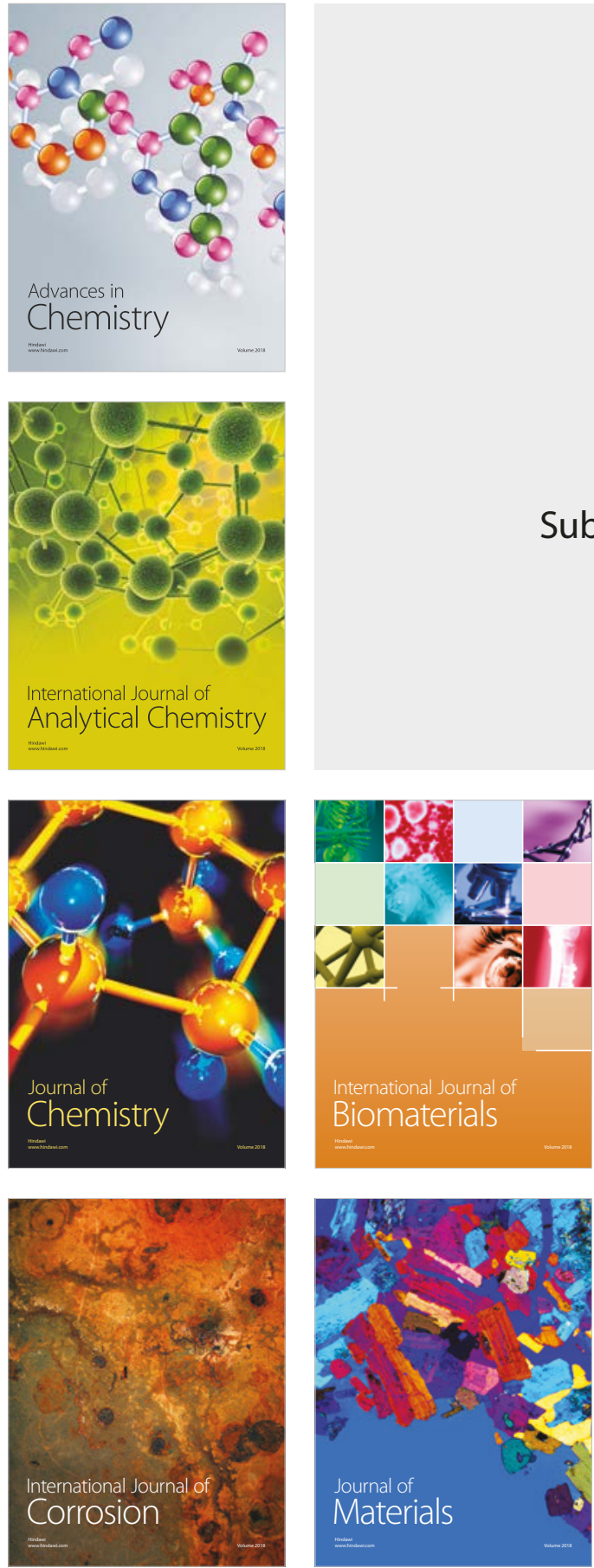

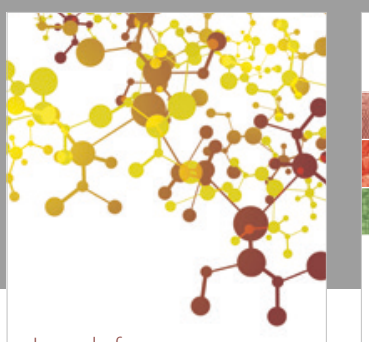

Journal of

Applied Chemistry
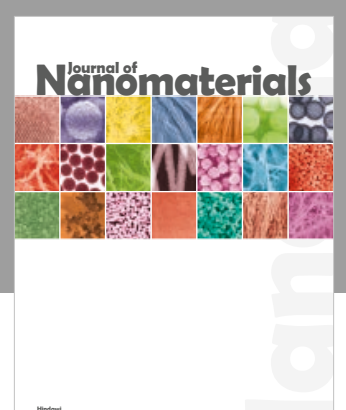

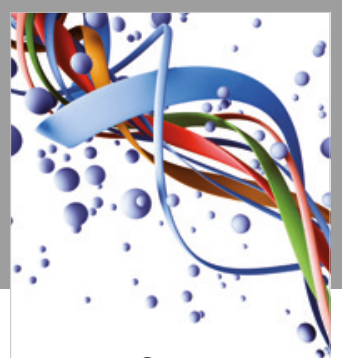

Scientifica

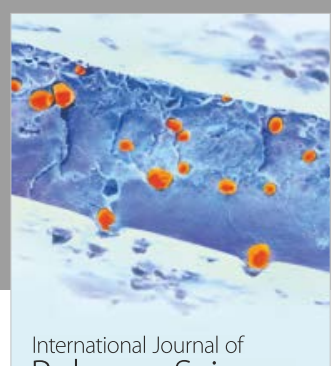

Polymer Science

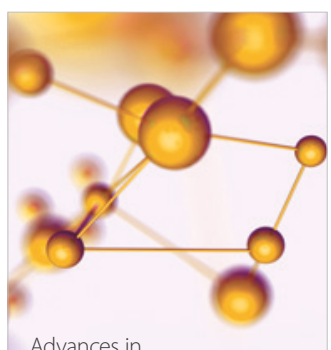

Physical Chemistry
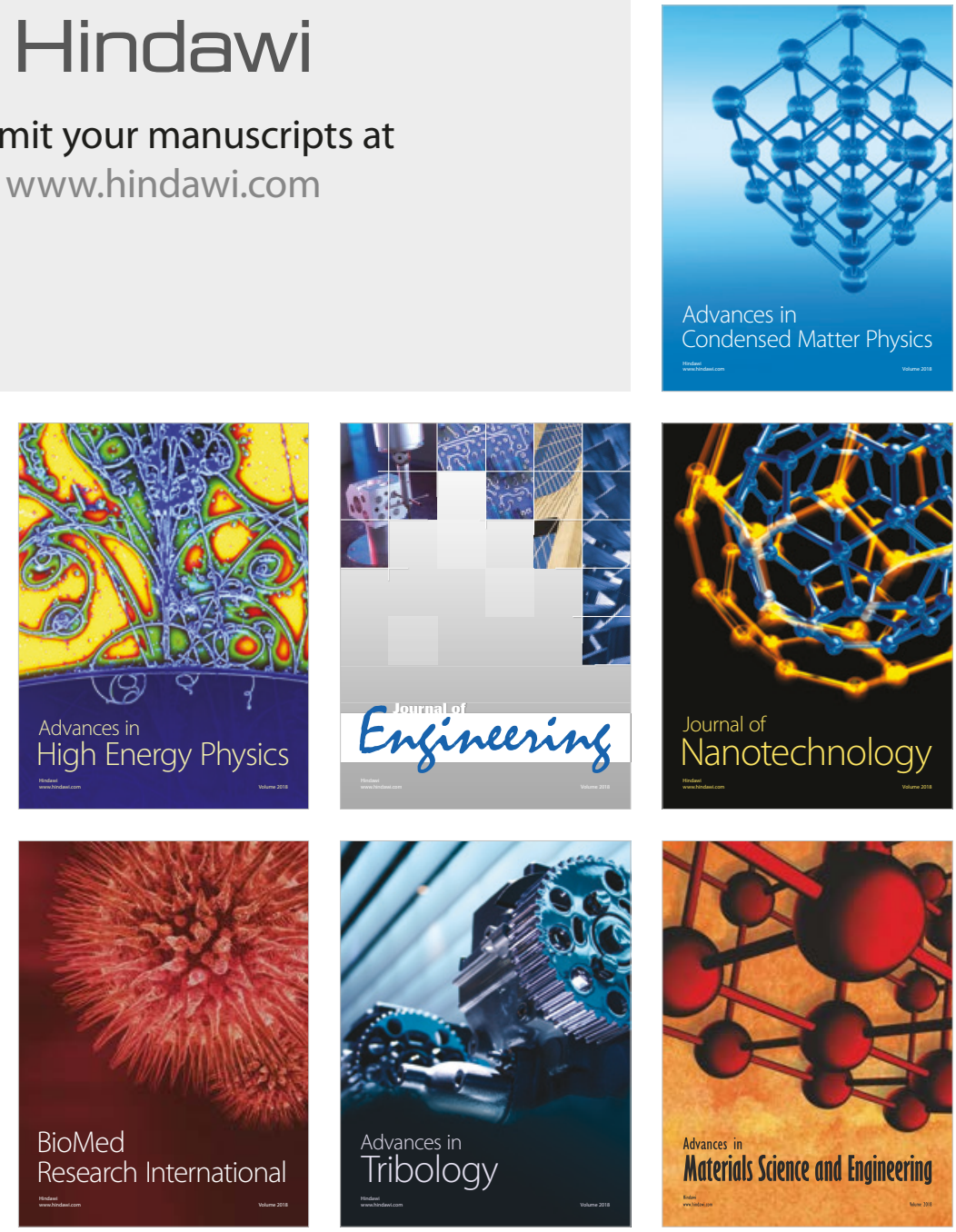